九州大学学術情報リポジトリ

Kyushu University Institutional Repository

Development of an Automatic Detection System for Knots Appearing on the Surface of Sugi Laminae with a Two-Dimensional Three-Charge Couple Device Color Camera

Ohuchi, Takeshi

Faculty of Agriculture, Kyushu University

Akasaka, Ryo

Faculty of Humanities, Kyushu Lutheran College

Suga, Kazumi

Faculty of Agriculture, Kyushu University

Murase, Yasuhide

Faculty of Agriculture, Kyushu University

https://doi.org/10.5109/4705

出版情報: 九州大学大学院農学研究院紀要. 51 (1)，pp.29-32，2006-02-01. Faculty of Agriculture， Kyushu University

バージョン :

権利関係 : 


\title{
Development of an Automatic Detection System for Knots Appearing on the Surface of Sugi Laminae with a Two-Dimensional Three-Charge Couple Device Color Camera
}

\author{
Takeshi OHUCHI*, Ryo AKASAKA ${ }^{1}$, Kazumi SUGA ${ }^{2}$ \\ and Yasuhide MURASE
}

\author{
Laboratory of Wood Material Technology, Division of Biomaterial Science, Department of Forest and \\ Forest Products Sciences, Faculty of Agriculture, Kyushu University, \\ Fukuoka 812-8581, Japanese \\ (Received October 31, 2005 and accepted November 16, 2005)
}

\begin{abstract}
The laminae grading for structural glulam timber is restricted by the bending strength and the ratio of knot diameter according to Japanese Agricultural Standard (JAS). However, visual grading is done by workers in most manufacturing factories because there are no clear regulations regarding the measuring method of the ratio of knot diameter. Therefore, the development of a system that could automatically detect knots on a material's surface is very desirable. In this study, a system for automatically detecting the shape (position and area) of knots, which appear on the laminae's surface with a two-dimensional three-Charge Couple Device (CCD) color camera, was developed. The main results obtained are summarized as follows: (1) an automatic detection system for knots appearing on the surface of wood was constructed; (2) this system was composed of a picture-processing device (a two-dimensional three-CCD color camera and controller), lighting equipment and a personal computer (PC) which controls all devices and collects sampling data; (3) the system could measure the ratio of knot diameter and detect the existence of knot, and the average measurement time of one image was about 2.6 seconds. Therefore, this system could work at a feed speed of $77 \mathrm{~mm} / \mathrm{s}$.
\end{abstract}

\section{INTRODUCTION}

Knots often appear on the surfaces of various wood and wood-based materials such as timber, columns, and laminae made from sugi (Cryptomeria japonica D. Don). These knots greatly influence the wood's strength when the sugi laminae are used as structural glulam laminae. In particular, cracks occur easily when tensile force is applied to laminae with knots used on the external layer of structural glulam timber. As a result, the strength properties decrease remarkably. Laminae grading is restricted by the bending strength and the ratio of knot diameter according to the Japanese Agricultural Standard (JAS). However, visual grading is done by workers in most manufacturing factories because there are no clear regulations regarding the measuring method of the ratio of knot diameter. Therefore, individual variation is caused by the use of different measurers, and the grading work is conducted inefficiently.

The development of a system that could automatically detect knots on a material's surface is very desirable. In a previous study on the detection of wood knots, the detection of knots with a one-dimensional image sensor was investigated (Wada, 1991-93a, b). A method of identifying knots with a two-dimensional image sensor has also been examined (Iwasaki et al, 1991). Moreover, many studies have been conducted in the

\footnotetext{
${ }^{1}$ Faculty of Humanities, Kyushu Lutheran College.

2 Laboratory of Wood Material Technology, Division of Biomaterial Science, Department of Forest and Forest Products Sciences, Faculty of Agriculture, Kyushu University

* Corresponding author (E-mail: tohuchi@agr.kyushu-u.ac.jp)
}

past (Hu et al, 2004 ; Kinoshita et al, 2000 ; Kodama et al, 1993 ; Kodama et al, 1993 ; Sadoh et al, 1993 ; Yang et al, 2002). However, the detection of knots with a two-dimensional color image processor has not been examined.

In this study, we paid attention to the laminae for sugi structural glulam timber, which is used often in Japan, and developed a system for automatically detecting the shape (position and area) of knots that appear on the laminae's surface with a two-dimensional three-charge couple device (CCD) color camera. Verification experiments of this system were also carried out.

\section{AUTOMATIC KNOT DETECTION SYSTEM}

\section{Outline of the system}

Figure 1 shows a schematic diagram of the system for automatically detecting knots. This system was com-

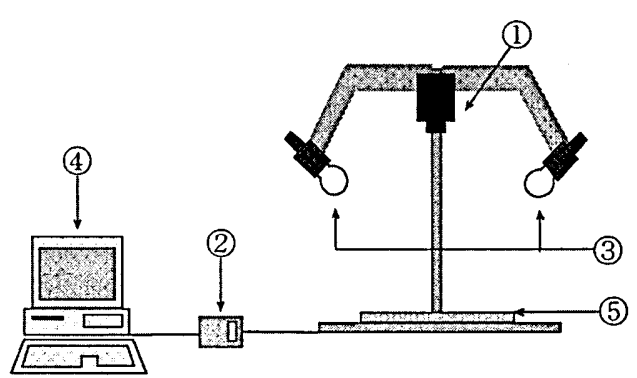

Fig. 1. Schematic diagram of the system for automatically detecting knots.

Legend : (1) : Three-CCD color camera, (2) : Controller, (3): Lighting equipment, (4) : Personal computer, (5) : Specimen. 
posed of a picture-processing device, lighting equipment, and a personal computer (PC) that controls all devices and collects sampling data. The picture-processing device was composed of a three-CCD color camera and controller.

\section{Automatic knot detection program}

The automatic knot detection program of this system was made using Visual Basic version 6.0 (VB). A flow-chart of the detection process in this system is shown in Fig. 2. The detection screen is shown in Fig. 3. As the first steps of the detection process, a picture -processing device loads the image of the wood surface having knots, and the color information of the wood surface is analyzed from the image. Then, binarization, filtering, and labeling processing are performed, respectively. By this process, the knot is detected. Each step of the processing method is described in greater detail below.

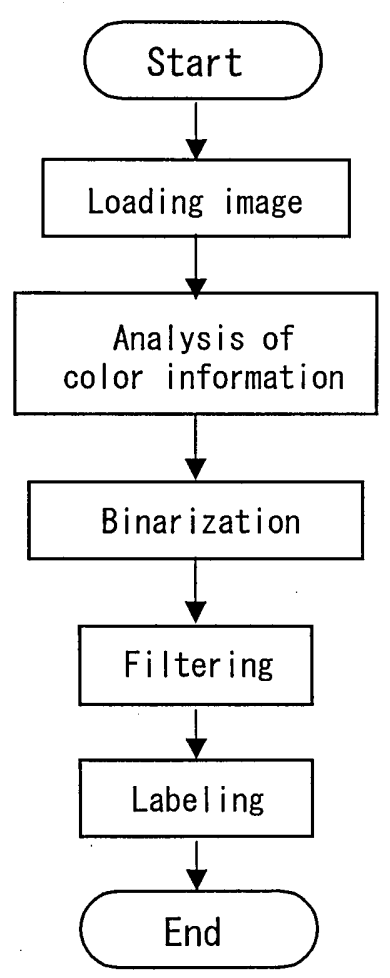

Fig. 2. Flow-chart of the detection process in this system.

\section{Image loading}

The image on the wood surface taken by a three-CCD color camera is loaded into the PC as the digital image data of $640 \times 480$ pixels through the image I/O (input output) interface board. This image is reduced to $160 \times 120$ pixels to increase the processing speed, and it is displayed on detection screen (1) (Fig. 3).

\section{Analysis of color information and binarization}

From all pixels of the load image data, color information on red (R), green (G), and blue (B) is extracted by using the point-method of VB. The best threshold for the detection of the knot is selected based on extracted color information, and binarization is per- formed. In this processing, if color information on the pixel is smaller than that of the threshold, it is converted to a black image, and if it is equal to or larger than the threshold, it is converted to a white image. The results are displayed on detection screen (2) (Fig. 3). From the result of a preliminary experiment, this system adopted the threshold of $153(\mathrm{R})$ as the best value for detecting knots.

\section{Filtering}

To remove noises other than the extracted knot, the image is filtered after it is binarized. As a result, the outline of the knot is made clearer. In the filtering we used in this system, the color information on both the pixel that shows color above the threshold and the eight pixels that are adjacent to it is examined, as shown in Fig. 4. The color information on these nine pixels is permuted in descending order, and the color information of the original colored pixel (4-pixel) is then replaced with the fifth permutation of the color information (1-pixel) as the mean value. After the above-mentioned processing had been performed on all pixels in the image, the image is displayed on detection screen (3) (Fig. 3).

Labeling

To distinguish the individual knots when there are a lot of knots in the same image, labeling of the pixels con-

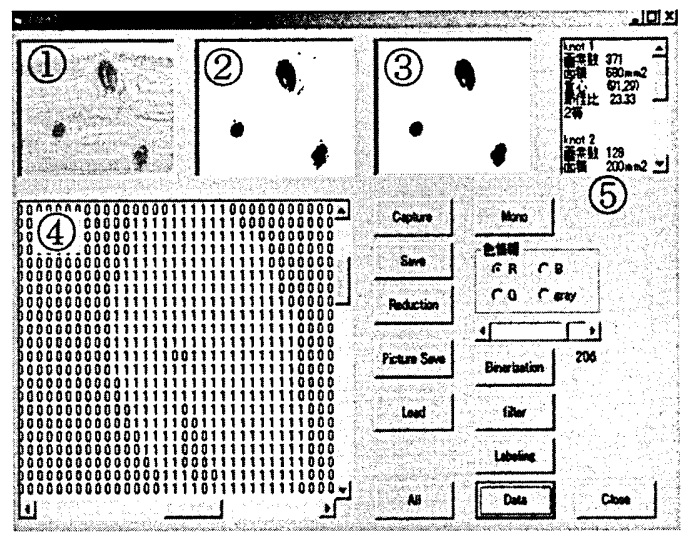

Fig. 3. A detection screen of an automatic knot detection program.

Legend : (1): Image of wood surface, (2): Image after binarization, (3) : Image after filtering, (4) : Labeling information, (5) : Results of measurement.

Replacement of color information on 4 and 1

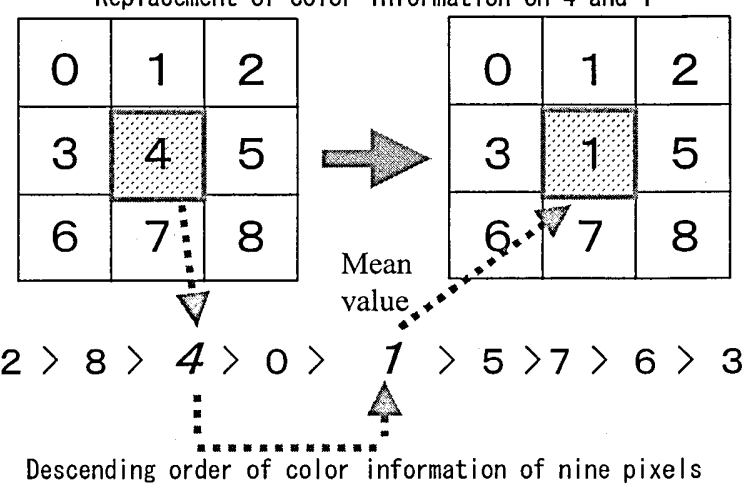

Fig. 4. A method of filtering in this system. 


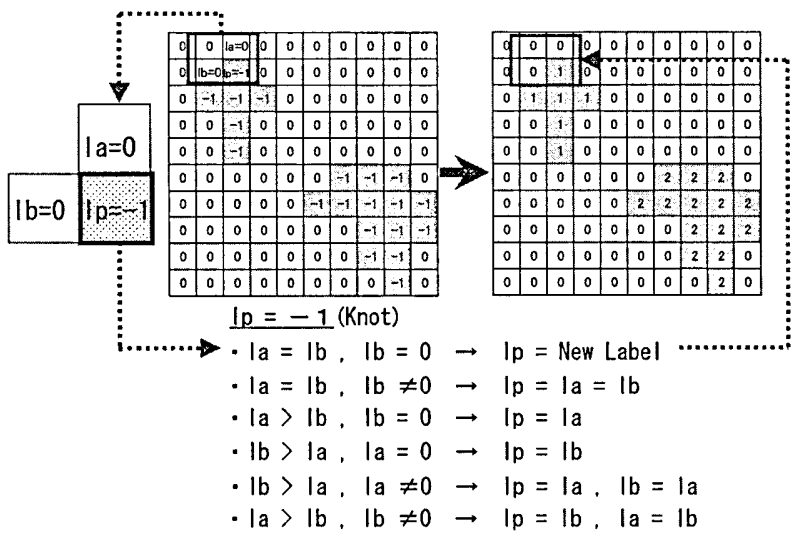

Fig. 5. A method of labeling in this system.

nected as a knot is performed, and each knot is distinguished and recognized. This is done by comparing color information on a given pixel (lp), paying attention to color information on the pixel above pixel $1 p$ (upper pixel, la) and the pixel below pixel $1 p$ (lower pixel, lb), as shown in Fig. 5. The relationship of the color information for $\mathrm{lp}$, la, and lb corresponds to any of six conditions, as shown in Fig. 5, and processing satisfying each condition is performed. This operation is performed for the entire image. As a result, labeling information obtained by this processing is displayed on detection screen (4) (Fig. 3). The pixel to which each label is attached is totaled, and the area of a knot is calculated. The center of gravity and the ratio of the knot diameter are then calculated from pixel coordinates. In addition, the grading is conducted based on the ratio of knot diameter, and these results are displayed on detection screen (5) (Fig. 3).

\section{VERIFICATION EXPERIMENT}

\section{Work materials}

Sugi laminae (150 $\mathrm{mm}$ in width, $28 \mathrm{~mm}$ in thickness) for structural glulam timber were used as specimens in this experiment. Sixteen specimens were prepared: seven specimens (Live) had only live knots on the 200-mm-long surface, six specimens (Dead) had only dead knots, and three specimens (Live +Dead) had both live and dead knots.

\section{Experimental method}

The verification experiment was conducted by comparing the ratio of the knot diameter that had been obtained with a manual measurement and the measurement using this system. In this manual measurement, the maximum length of the knot in the direction of width was measured with a digital caliper, and the ratio of knot diameter was calculated. In another measurement using this system, to adjust the length of one pixel to $1.25 \mathrm{~mm}$ on the specimen surface, we set the distance of a three-CCD color camera and specimen to $645 \mathrm{~mm}$ and the illuminance of the lighting equipment to 2190 LUX and measured the ratio of the knot diameter.

\section{RESULTS AND DISCUSSION}

Figure 6 shows the ratio of the knot diameter obtained manually and the measurement obtained using this system. From these results, in the case of each knot, we verified that both measurements indicate almost the same value. Figure 7 shows the relationship between the ratio of the knot diameter obtained manually and the ratio obtained with this system. A high correlation was shown between the measurements made by the two methods, which indicates that the proposed system can detect knots and measure the ratio of each knot's diameter. In this experiment, the average measurement time of one image is about 2.6 'seconds, which would correspond in the manufacturing process to a feed speed of $77 \mathrm{~mm} / \mathrm{s}$. The system will need to be improved so it is useful in higher-speed manufacturing processes in the future.

\section{CONCLUSIONS}

In this study, a system was developed that can automatically detect the shape (position and area) of knots that appear on the surface of laminae with a two-dimensional three-CCD color camera. The main results obtained are summarized as follows:

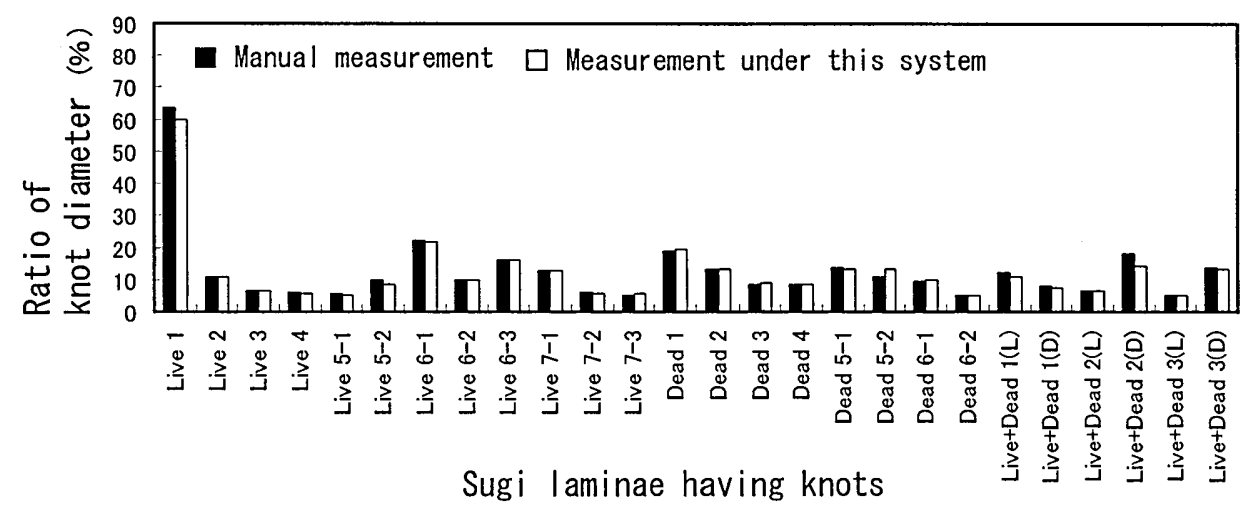

Fig. 6. The ratio of the knot diameter obtained manually and the measurement obtained using this system. 


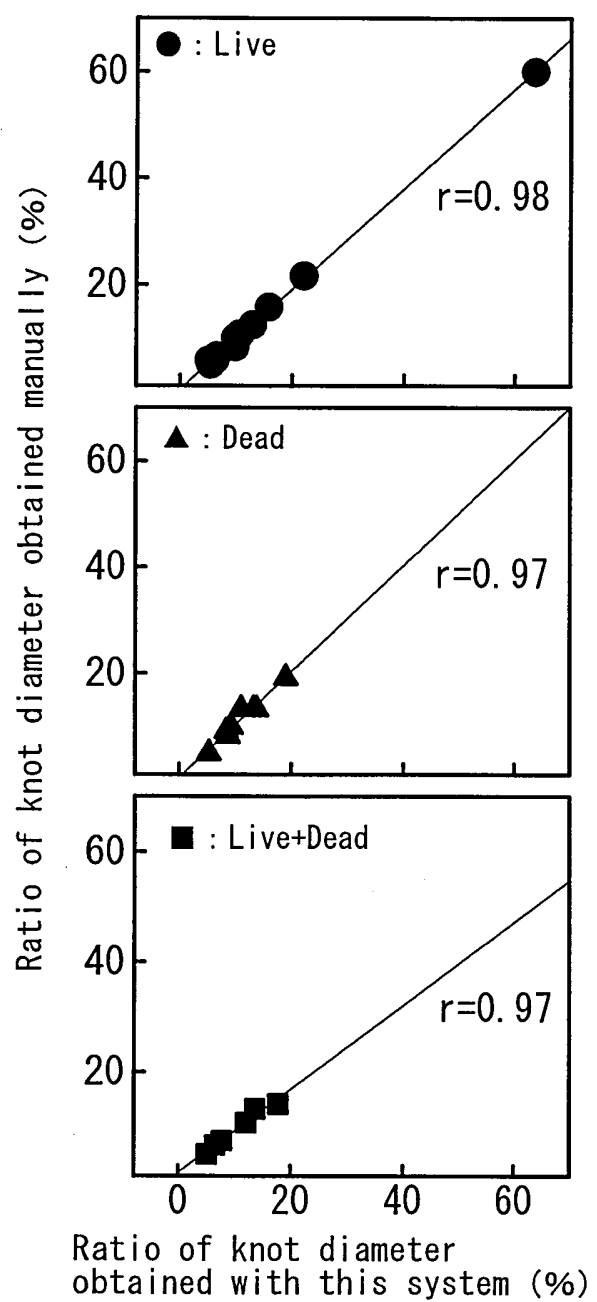

Fig. 7. Relationship between the ratio of the knot diameter obtained manually and the ratio obtained with this system.
1. The described system was composed of a picture-processing device (a two-dimensional three-CCD color camera and controller), lighting equipment, and a personal computer (PC) that controls all devices and collects sampling data.

2. The system could detect knots and measure the ratio of a knot's diameter, and the average measurement time of one image was about 2.6 seconds. Therefore, this system could work at a feed speed of $77 \mathrm{~mm} / \mathrm{s}$.

\section{REFERENCES}

Iwasaki, S., T. Sadoh 1991 Measurements of Knots in Hinoki and Sugi Lumbers by the Optical Scanning Method. Mokuzai Gakkaishi, 37(11): 999-1003

Hu, C., C.Tanaka, T. Ohtani 2004 Locating and identifying sound knots and dead knots on sugi by the rule-based color vision system. J. Wood Sci., 50(2): 115-122

Kinoshita, N., M. Yoshinobu 2000 Detection of wood properties using heating and cooling method II: Detection of knots on wood surface. Mokuzai Gakkaishi, 46(2): 155-160

Kodama, Y., T. Akishika 1993 Non-Destructive Inspection of Defects in Wood by Use of the Pulse-Echo Technique of Ultrasonic Waves I. Measurements of enclosed knots. Mokuzai Gakkaishi, 39(1): 7-12

Sadoh, T., K. Murata 1993 Detection of Knots in Hinoki and Karamatsu Lumber by Thermography. Mokuzai Gakkaishi, 39(1): $13-18$

Wada, H. 1991a The Detection of Knots Appearing on a Douglas-Fir (Pseudotsuga menziesii) Lamina Utilizing a One-Dimensional CCD Sensor. Mokuzai Gakkaishi, 37(3): 206-210

Wada, H. 1993b The Detection of Knots Appearing on a Hinoki (Chamaecyparis obtusa) Lamina Utilizing a One-Dimensiona1 CCD Sensor. On surface conditions and measuring speed. Mokuzai Gakkaishi, 39(1): 19-23

Yang, X., Y. Ishimaru, I. Iida 2002 Application of modal analysis by the transfer function to nondestructive testing of wood III: Detection of knots and estimation of elastic modulus distribution in wood by the curvature ratio of the flexural vibration wave shape. Mokuzai Gakkaishi, 48(1): 16-22 